POLA MAKAN MENGANDUNG ZAT PURIN BERLEBIHAN MENINGKATKAN PREVALENSI GOUT ARTHRITIS PADA MASYARAKAT DI DESA KOTABUNAN

\author{
Rizky Nurul Fauziah, Herlina P. Memah, Lorrien G. Runtu \\ Politeknik Kesehatan Kemenkes Manado \\ e-Mail : qiqyfauziah@gmail.com
}

\begin{abstract}
ABSTRAK
Latar belakang : Gout Arthritis merupakan penyakit radang pada sendi yang menimbulkan rasa nyeri sangat hebat, bengkak, kadang kemerahan dan sulit untuk digerakkan dan bila berlangsung dalam jangka waktu lama dapat menyebabkan deformitas pada sendi yang terkena. Tujuan : Mengetahui hubungan pola makan dengan kejadian gout arthritis. Desain yang digunakan berupa correlation. Metode : Jenis penelitian adalah penelitian deskriptif analitik dengan pendekatan cross - sectional. lokasi penelitian di Desa Kotabunan Kecamatan Kotabunan Kabupaten Bolaang Mongondow Timur sejak tanggal 21 Juli sampai 23 Juli 2018. Teknik pengambilan sampel menggunakan total sampel dengan responden 49 orang. Instrument menggunakan kuesioner food recall $2 \times 24$ jam. Hasil : Uji statistic dengan chi-square dengan tingkat kemaknaan $(\alpha) 0,05$. Hasil uji korelasi diperoleh $\rho=0,002$. Kesimpulan dari penelitian ini yaitu terdapat hubungan antara pola makan dengan kejadian gout arthritis, dimana semakin sering mengkonsumsi makanan berkadar purin tinggi semakin tinggi nilai kadar asam urat. Saran : Masyarakat dapat menjaga pola makan dengan baik mengingat masih banyaknya masyarakat yang kurang menjaga pola makan sehingga berakibat peningkatan kadar asam urat dalam darah.
\end{abstract}

Kata kunci: Pola Makan; Zat Purin Berlebihan; Gout Arthritis

\title{
EATING PATTERN CONTAINS EXCESSIVE PURIN SUBSTANCE IMPROVING GOUT ARTHRITIS PREVALENCE IN COMMUNITIES IN KOTABUNAN VILLAGE
}

\author{
Rizky Nurul Fauziah, Herlina P. Memah, Lorrien G. Runtu \\ Health Ministry Polytechnic of Manado \\ e-Mail: qiqyfauziah@gmail.com
}

\begin{abstract}
Background: Gout Arthritis is an inflammatory disease in the joints that causes extreme pain, swelling, sometimes redness and is difficult to move and if it lasts for a long time it can cause deformity in the affected joint. Objective: To determine the relationship between diet and gout arthritis. The design used is correlation. Method: This type of research is analytic descriptive research with cross-sectional approach. the location of the study was in Kotabunan Village, Kotabunan Subdistrict, Bolaang Mongondow Timur Regency from July 21 to July 23, 2018. The
\end{abstract}


sampling technique used a total sample with 49 respondents. The instrument uses a food recall questionnaire $2 \times 24$ hours. Results: Statistical test with chi-square with significance level $(\alpha)$ 0.05 . Correlation test results obtained $\rho=0.002$. The conclusion : This study is that there is a relationship between diet and the incidence of gout arthritis, where the more often the consumption of high purine content, the higher the value of uric acid levels. Suggestion: People can maintain their diet well considering there are still many people who do not maintain their diet so that it results in increased levels of uric acid in the blood.

Keywords: Diet; Excessive Purine Substances; Gout Arthritis

\section{PENDAHULUAN}

Gout Arthritis merupakan penyakit radang pada sendi yang menimbulkan rasa nyeri sangat hebat, bengkak, kadang kemerahan dan sulit untuk digerakkan. (Perhimpunan Reumatologi Indonesia, 2016). Berdasarkan jurnal penelitian Best Practice \& Research Clinical Rheumatology pada tahun 2010, terhadap 4683 orang dewasa menunjukkan bahwa angka prevalensi gout dan hiperurisemia di Indonesia adalah masing-masing 1,7 dan 24,3 \% (E.U.R Smith, 2010).

Organisasi kesehatan dunia (WHO) melaporkan bahwa 20\% atau lebih dari 355 juta penduduk dunia terserang penyakit Gout Arthritis, dimana 5-10\% adalah mereka yang berusia 5-20 tahun dan 20\% mereka yang berusia 55 tahun, artinya 1 dari 6 orang di dunia menderita Gout Arthritis.

Hasil Riskesdas 2013 mengungkapkan bahwa prevelensi penyakit Gout Arthritis di Indonesia adalah $11,9 \%$ dan di Sulawesi
Utara adalah 10,3 \%. Data yang diperoleh dari Puskesmas Kotabunan Kabupaten Bolaang Mongondow TImur didapatkan data jumlah penderita Gout Arthritis pada tahun 2016 berjumlah 86 kasus, dan pada tahun 2017 berjumlah 74 kasus.

Studi dokumentasi yang dilakukan, 10 orang yang menderita penyakit Gout Arthritis yang ditemui saat berkunjung di Puskesmas Kotabunan dan dilakukan wawancara tentang kebiasaan pola makan mereka sehari-hari, didapati hanya 2 orang yang mematuhi pola makan rendah purin, sedangkan 8 orang lainnya masih mengkonsumsi makanan yang tinggi purin, seperti sayuran hijau, kacang-kacangan dan makanan laut atau seafood yang memiliki kadar purin yang tinggi.

Gout arthritis bila berlangsung dalam jangka waktu lama dapat menyebabkan komplikasi deformitas pada sendi yang terkena gout arthritis. Berdasarkan hal tersebut maka peneliti tertarik untuk 
melakukan penelitian tentang "Hubungan Pola Makan Dengan Kejadian Gout Arthritis pada penderita Gout Arthritis Di Desa Kotabunan Kecamatan Kotabunan Kabupaten Bolaang Mongondow Timur"

\section{METODE PENELITIAN}

Jenis penelitian yang digunakan adalah penelitian deskriptif analitik dengan pendekatan cross-sectional (potong lintang) merupakan rancangan penelitian yang menekankan waktu dan pengukuran/observasi data variable independen dan dependen hanya satu kali pada satu saat (Nursalam, 2013).Penelitian ini untuk mengetahui hubungan pola makan dengan kejadian gout arthritis di Desa Kotabunan Kecamatan Kotabunan Kabupaten Bolaang Mongondow Timur.

Waktu penelitian pada tanggal 21-23 Juli tahun 2018. Populasi dalam penelitian ini adalah penderita gout arthritis di Desa Kotabunan Kecamatan Kotabunan Kabupaten Bolaang Mongondow Timur yang berjumlah 49 responden. Teknik sampling yang digunakan adalah total sampling dengan jumlah sampel. Variabel Independen (bebas) adalah pola makan. sedangkan Variabel Dependen (terikat) kejadian gout arthritis di Desa Kotabunan Kecamatan
Kotabunan Kabupaten Bolaang Mongondow Timur.

Instrument penelitian menggunakan metode food recall. Prinsip dari metode food recall, dilakukan dengan peneliti mengajukan pertanyaan tentang apa saja jenis dan jumlah makanan yang dikonsumsi responden selama $2 \times 24$ jam dan dilakukan pencatatan yang di isi oleh responden. Dengan metode ini responden diminta untuk mengingat kembali apa saja yang sudah dikonsumsi. Setelah data terkumpul, dianalisis dengan menggunakan analisa univariate dan bivariate. Dengan derajat kesalahan $0.05 \%$ atau derajat kemaknaan $95 \%$.

\section{HASIL PENELITIAN}

Hasil penelitian univariate menyajikan karakteristik responden berdasarkan pendidikan, umur, pekerjaan dan jenis kelamin. Sedangkan analisa bivariate menyajikan tentang pola makan dengan kejadian gout arthritis di Desa Kotabunan.

Tabel 1 Distribusi Responden Menurut Umur

\begin{tabular}{cccc}
\hline No & Umur & frekuensi & $\begin{array}{c}\text { Persentase } \\
\%\end{array}$ \\
\hline 1 & $45-59$ & 37 & 75.52 \\
2 & $60-74$ & 11 & 22.44 \\
3 & $75-90$ & 1 & 2.04 \\
\hline & Jumlah & 49 & 100 \\
\hline
\end{tabular}


Berdasarkan tabel 1, menunjukkan

75.52 \%.usia $45-59$ tahun.

Tabel 2 Distribusi Responden Menurut Jenis Kelamin

\begin{tabular}{lccc}
\hline No & $\begin{array}{c}\text { Jenis } \\
\text { kelamin }\end{array}$ & Frekuensi & Persen \\
\hline 1. & Laki-laki & 31 & 63.26 \\
2. & Perempuan & 18 & 36.74 \\
\hline & Total & 49 & $100 \%$ \\
\hline
\end{tabular}

Berdasarkan tabel 2, mengambarkan $63.26 \%$ laki-laki).

Tabel 3 Distribusi Frekuensi Responden Menurut Pendidikan

\begin{tabular}{cccc}
\hline No & Pendidikan & Frekuensi & Persen \\
\hline 1. & SD & 23 & $46.94 \%$ \\
2. & SMP & 17 & $34.70 \%$ \\
3. & SMA & 7 & $14.28 \%$ \\
4. & Perguruan & 2 & $4.08 \%$ \\
& tinggi & & \\
\hline & Total & 49 & $100 \%$ \\
\hline
\end{tabular}

Berdasarkan tabel 3 diatas menunjukan dari 49 responden $46.94 \%$ pendidikan dasar .
Tabel 4 Distribusi Frekuensi Responden Menurut Pekerjaan

\begin{tabular}{|c|c|c|c|}
\hline No & Pekerjaan & Frekuensi & Persen \\
\hline 1. & Petani & 26 & $53.06 \%$ \\
\hline 2. & Nelayan & 5 & $10.20 \%$ \\
\hline 3. & Wiraswasta & 4 & $8.16 \%$ \\
\hline 4. & Karyawan & 1 & $2.04 \%$ \\
\hline \multirow[t]{2}{*}{5.} & IRT & 13 & $26.54 \%$ \\
\hline & Total & 49 & $100 \%$ \\
\hline
\end{tabular}

49 responden 51.02\% bekerja sebagai petani.

Tabel 5 Distribusi Responden Berdasarkan Pola Makan

\begin{tabular}{cccc}
\hline No & Pola makan & Frekuensi & Persen \\
\hline 1. & Baik & 19 & $38.78 \%$ \\
2. & Kurang baik & 30 & $61.22 \%$ \\
\hline & Total & 49 & $100 \%$
\end{tabular}

Berdasarkan tabel 5, menunjukan dari 49 sampel $61.22 \%$ pola makan kuran baik.

Tabel 6 Distribusi Responden Berdasarkan Kejadian Gout Arthritis

\begin{tabular}{|c|c|c|c|}
\hline No & $\begin{array}{c}\text { Kejadian Gout } \\
\text { Arthritis }\end{array}$ & Frekuensi & Persen \\
\hline 1. & Tinggi & 31 & $63.27 \%$ \\
\hline 2. & Normal & 18 & $36.73 \%$ \\
\hline \multicolumn{2}{|r|}{ Total } & 49 & $100 \%$ \\
\hline \multicolumn{3}{|c|}{ Berdasarkan tabel 6 , dari 49} & 9 sampel \\
\hline & ukan 63.26 & $\%$ menderita & gout \\
\hline
\end{tabular}


Tabel 7 Tabulasi Silang antara Hubungan Pola Makan dengan Kejadian Gout Arthritis

\begin{tabular}{|c|c|c|c|c|c|c|c|}
\hline \multirow[t]{2}{*}{ Pola Makan } & \multicolumn{4}{|c|}{ Kejadian Gout Arthritis } & \multirow[t]{2}{*}{ Total } & \multirow[t]{2}{*}{ Persen } & \multirow{2}{*}{$\begin{array}{c}\rho- \\
\text { value }\end{array}$} \\
\hline & Normal & $\%$ & Tinggi & $\%$ & & & \\
\hline Baik & 12 & 24.49 & 7 & 14.29 & 19 & 38.78 & 0,002 \\
\hline Kurang baik & 6 & 12.24 & 24 & 48.98 & 30 & 61.22 & \\
\hline Total & 18 & 36.73 & 31 & 63.27 & 49 & 100 & \\
\hline
\end{tabular}

Dari tabel 7, menunjukkan 19 responden dengan pola makan baik terdapat $24.49 \%$ responden dengan gout arthritis normal dan $14.29 \%$ responden dengan gout arthritis tinggi. Dari 30 responden dengan pola makan kurang baik terdapat $12.24 \%$ responden dengan gout arthritis normal dan $48.98 \%$ responden dengan gout arthritis tinggi. Uji yang digunakan adalah uji chisquare (pearson chi-square).

Dari uji chi-square didapatkan hasil $x^{2}$ hitung sebesar 9.344 dan $x^{2}$ tabel sebesar 3.84 pada $\mathrm{df}=1$ dan $\alpha \leq 0.05$, hasil uji dianalisis $\rho$ $=0.002$. Dari hasil tersebut maka dapat disimpulkan Ho di tolak dan Ha diterima jadi terdapat hubungan antara pola makan dengan kejadian gout arthritis di Desa Kotabunan Kecamatan Kotabunan Kabupaten Bolaang Mongondow Timur.

\section{PEMBAHASAN}

Berdasarkan hasil penelitian pola makan dengan kejadian gout arthritis di Desa Kotabunan Kecamatan Kotabunan
Kabupaten Bolaang Mongondow Timur, data yang diperoleh dari kuesioner yang telah diolah dan akan membahas permasalahan yang ada Berdasarkan karakteristik responden Umur, jenis kelamin, Pendidikan, Pekerjaan di Desa Kotabunan Kecamatan Kotabunan Kabupaten Bolaang Mongondow Timur.

Analisa Univariat

1) Umur

Berdasarkan hasil penelitian Di Desa Kotabunan Kecamatan Kotabunan Kabupaten Bolaang Mongondow Timur, dari responden yang berumur 45 sampai 90 tahun yang memiliki pola makan baik yaitu 19 responden (38.78 $\%)$, dan yang memiliki pola makan kurang baik yaitu 30 responden $(61.22$ \%) dengan total responden 49 responden. Artinya gout arthritis banyak diderita oleh responden dengan usia pertengahan keatas. Menurut Albadroe (2007), dari semua faktor 
resiko terjadinya gout arthritis bahwa faktor yang terkuat adalah faktor usia, prevelensi dan beratnya gout arthritis akan semakin meningkat seiring dengan bertambahnya umur, artinya semakin tua seseorang maka resiko terjadinya gout arthritis akan semakin meningkat.

2) Jenis Kelamin

Berdasarkan frekuensi jenis kelamin menunjukan bahwa dari 49 responden terbanyak dengan jenis kelamin laki-laki 31 responden (63.26 \%) dan perempuan berjumlah 18 responden (36.74 \%). Artinya gout arthritis banyak menyerang responden yang berjenis kelamin laki-laki. Menurut Mc Adam-De Marco et al (2013), jenis kelamin juga mempengaruhi gout arthrititis, prevelensi pria lebih tinggi daripada wanita untuk mengalami gout arthritis. Hal ini dikarenakan wanita memiliki hormone estrogen yang membantu dalam ekskresi asam urat.

3) Pendidikan

Berdasarkan frekuensi Pendidikan menunjukan dari 49 responden dalam penelitian ditemukan jumlah tertinggi berdasarkan pendidikan terakhir yaitu SD sebanyak 23 responden (46.94\%), ini menunjukkan dari segi pendidikan sebagian responden sangat kurang. Pendidikan yang kurang mempengaruhi ilmu yang didapat sehingga proses penyampaian informasi kesehatan sangat kurang, hal ini didukung oleh pendapat Redja Mulyahardjo (dalam Sulistiawan, 2008). Pendidikan adalah segala pengalaman belajar yang berlangsung dalam lingkungan dan sepanjang hidup serta segala situasi hidup yang mempengaruhi pertumbuhan individu.

4) Pekerjaan

Berdasarkan frekuensi pekerjaan menunjukan dari 49 responden dalam penelitian ini ditemukan jumlah tertinggi pekerjaan yaitu Petani sebanyak 26 responden (53.06 \%). Ini dikarenakan pekerjaan berhubungan dengan status sosial ekonomi atau pendapatan keluarga yang juga berpengaruh dalam pemanfaatan pelayanan kesehatan yang ada. Menurut Lodahl \& Kejner dalam Aryaningtyas \& Suharti (2013). Pekerjaan didefinisikan sebagai sesuatu yang mana seseorang mengidentifikasi secara psikologis dengan pekerjaannya atau pentingnya pekerjaan dalam citra diri individu. 
a. Pola Makan

Berdasarkan frekuensi pola makan responden menunjukan dari 49 responden ditemukan pola makan yang baik dengan jumlah 19 responden (38.77\%), sedangkan pola makan kurang baik dengan jumlah 30 responden (61.22\%). Ini menunjukkan masih banyak responden yang memiliki pola makan yang kurang baik. Menurut Sulistyoningsih (2011), pola makan didefinisikan sebagai karakteristk dari kegiatan makan yang berulang kali dilakukan individu atau setiap orang dalam memenuhi kebutuhan makanan yang terdiri dari tiga komponen yaitu jenis makan, frekuensi makan, dan jumlah makan.

b. Kejadian Gout Arthritis

Berdasarkan frekuensi kejadian gout arthritis responden menunjukan dari 49 sampel ditemukan yang termasuk gout arthritis tinggi dengan jumlah 31 responden (63.26 \%), sedangkan gout arthritis normal dengan jumlah 18 responden (36.73 \%). Ini menunjukkan banyak responden yang ditemukan memiliki kadar asam urat yang tinggi. Menurut Mumpuni dan Wulandari 2012, Gout arthritis adalah penyakit yang menyerang persendianpersendian tubuh. Asam urat umumnya menyerang sendi jari tangan, tumit, kaki, siku, lutut dan pergelangan tangan.

\section{Analisa Bivariat}

Berdasarkan pada penelitian yang dilakukan pada tanggal 21-23 Juli 2018, didapatkan dari 19 responden dengan pola makan baik terdapat 12 responden dengan gout arthritis rendah dan 7 responden dengan gout arthritis tinggi. Dari 30 responden dengan pola makan kurang baik terdapat 6 responden dengan gout arthritis rendah dan 24 orang dengan gout arthritis tinggi. Diperoleh nilai $\rho=0,002$ yaitu lebih kecil dari $\alpha=0,05$ berarti bermakna, Jadi Ho ditolak dan Ha diterima. Hal ini menunjukan bahwa ada hubungan yang bermakna antara Pola Makan dengan Kejadian Gout Arthritis di Desa Kotabunan Kecamatan Kotabunan Kabupaten Bolaang Mongondow Timur. Penelitian yang saya lakukan ini juga memiliki kesamaan yang dilakukan oleh Ida untari \& Titin wijayanti, (2017), yang mengatakan terdapat hubungan yang cukup dan positif antara pola makan dengan penyakit gout, Andry, Saryono, Dan Upoyo A.S (2009), mengatakan terdapat hubungan 
antara pola makan dengan kadar asam urat pada pekerja kantor di Desa Karang Turi Kecamatan Bumi Ayu, Kabupaten Brebes.

\section{KESIMPULAN DAN SARAN}

Kesimpulan

1. Teridentifikasi pola makan pada penderita gout arthritis di Desa Kotabunan Kecamatan Kotabunan Kabupaten Bolaang Mongondow Timur masih kurang baik.

2. Teridentifikasi kejadian gout arthritis di Desa Kotabunan Kecamatan Kotabunan Kabupaten Bolaang Mongondow Timur masih tinggi.

3. Adanya hubungan pola makan dengan kejadian gout arthritis di Desa Kotabunan Kecamatan Kotabunan Kabupaten Bolaang Mongondow Timur dengan nilai $p=$ $0,002<0,05$.

Saran

1. Bagi masyarakat di Desa Kotabunan Untuk mengontrol dan meminimalkan kejadian gout arthritis, sebaiknya masyarakat Desa Kotabunan harus mengatur pola makan dan menjaga makanan yang dikonsumsi

2. Institusi Pelayanan Keperawatan

Kiranya hasil penelitian ini dapat memberikan gambaran mengenai hubungan pola makan dengan kejadian gout arthritis, sehingga institusi pelayanan keperawatan dapat memberikan pencegahan mengenai kejadian gout arthritis di Desa Kotabunan.

3. Institusi Pendidikan

Kiranya hasil penelitian ini dapat digunakan untuk bahan informasi bagi kepentingan pendidikan dan tambahan perpustakaan Politeknik Kesehatan Kemenkes Manado.

4. Bagi peneliti selanjutnya

Dapat melakukan penelitian tentang pola makan pada penderita gout arthritis dengan metode atau jenis penelitian yang berbeda, yang tidak terdapat dalam penelitian ini. Kekurangan dalam penelitian ini diharapkan agar bisa diteliti kedepannya. 


\section{DAFTAR PUSTAKA}

Andry, Saryono, Dan Upoyo A.S (2009). Analisis Faktor-Faktor Yang Mempengaruhi Kadar Asam Urat Pada Pekerja Kantor Di Desa Karang Turi, Kecamatan Bumi Ayu, Kabupaten Brebes. Jurnal keperawatan sodirman

Albadroe (2007). Arthritis rheumatoid. http://albadroe multiply.com/journal?\&;\& page star=160. Diperoleh tgl 19 juli 2018

Aryaningtyas, Aurilia Triami \& Suharti, Lieli. (2013). Keterlibatan Kerja sebagi Pemediasi Pengaruh Kepribadian Proaktif dan Oersepsi Dukungan Organisasi terhadap Kepuasan Kerja. JMK, Vol.15, Nomor 1, halaman 2332.

E.U.R. Smith (2010). Epidemiology of gout. An update, Best Practice and Research Clinical Rheumatology

Ida untari \& Titin wijayanti (2017). Hubungan antara pola makan dengan penyakit gout. Jurnal uad yogyakarta

Junaidi I (2012). Rematik Dan Asam Urat. Jakarta. PT Bhuana IImu Popular

McAdams-DeMarco MA, Law A, Maynard JW, Coresh J, Baer AN. (2013). Risk Factors for Incident Hyperuricemia during Mid-Adulthood in African American and White Men and Women Enrolled in the ARIC Cohort Study. BMC musculoskeletal disord. 14:347.

Misnadiarly. (2007). Rematik asam urathiperurisemia arthritis gout. Pustaka Obor Populer, Jakarta
Mudyahardjo, Redja (2008). Pengantar Pendidikan Sebuah Studi Awal tentang Dasar-dasar Pendidikan pada Umumnya da Pendidikan di Indonesia. Jakarta. Raja Grafindo Persada.

Notoatmodjo, S (2012). Metodelogi Penelitian Kesehatan. Jakarta: Rineka Cipta.

Nursalam, (2013). Konsep dan Penerapan Metodelogi Penelitian Keperawatan. Jakarta: Rineka Cipta.

Perhimpunan Reumatologi Indonesia (2016). Arthritis Gout Dan Asam Urat. Jakarta

Sulistyoningsih (2011). Gizi Untuk Kesehatan Ibu Dan Anak. Yogyakarta. Graha IImu 